\title{
RECENT SEISMOMETRICAL WORKS IN JAPAN
}

\author{
Shigeji Suyehiro, ${ }^{*}$ Masaji Ichikawa, ${ }^{*}$ and Kenshiro Tsumura ${ }^{* *}$ \\ *Seismological Division, Japan Meteorological Agency, \\ Tokyo, Japan \\ **Earthquake Research Institute, University of Tokyo, \\ Tokyo, Japan
}

(Received April 27, 1977; Revised October 5, 1977)

\begin{abstract}
In order to obtain data for conducting research on the earthquake prediction as well as to monitor the seismic activity in and near Japan, seismological networks have been strengthened by many national universities and agencies. Most stations are telemetered to centers where computerized location facilites are installed, and the telemetered records are processed on a real-time or nearly real-time basis. The structure of hypocentral distribution has been made very clear in many parts of Japan by the data obtained from the networks.

Based on the data by the Japan Meteorological Agency, many researches on the seismicity gap and variation in seismic velocity prior to the occurrence of major earthquakes have been made. The seismicity gap appears to be a positive factor to predict the area where a major earthquake will occur. On the other hand, both positive and negative results were obtained on the temporal variation in seismic velocity. In view of the present accuracy of observations, even the positive cases should be rechecked.
\end{abstract}

\section{Introduction}

Japan has a rather long history of the routine seismological observations. The Japan Meteorological Agency (JMA) started its routine observation in 1875 and later in 1926 deployed then very modern Wiechert seismographs at its 60 stations. It has been already half a century since that time and fairly good instrumental data for earthquakes in and near Japan have been accumulated.

Recently, JMA has been trying to enhance the overall sensitivity of its seismic network by adding high sensitivity stations on land and also on the ocean bottom. However, most of our past data are mainly for earthquakes of $M$ over 4.0, sometimes 4.5 for off-coast region.

On the other hand, universities started observations of micro-earthquakes in the 1960 's and especially based on the evidences obtained during the Matsushiro earthquake swarm, which suggested the importance of observations of micro-earthquakes in relation to prediction, the observation networks of micro-earthquakes have been much extended and strengthened by Hokkaido, Tohoku, Tokyo, Nagoya, Kyoto and Kochi Universities in their respective regions.

Recently, the National Research Center for Disaster Prevention also jointed micro-earthquake observation using very deep borehole seismometers near Tokyo. 
These networks are rather young and have only regional coverages, but are operating routinely, so that the accumulation of data is enormous, because of the high frequency of occurrence of micro-earthquakes.

In this paper, recent seismometrical works concerning earthquake prediction are briefly mentioned.

\section{Seismometrical Networks}

Dense regional or local networks for micro-earthquake observations have been established by many national universities and institutes. Most stations are telemetered to centers where computerized location facilities are installed, and telemetered records are processed on a real-time or nearly real-time basis.

By deployment of universities' micro-earthquake networks, the fine structure of hypocentral distribution has been made very much clearer in many parts of Japan (MAtsumura et al., 1973; TAKagi et al., 1977) (Fig. 1). One of the interesting results is presented in the present seminar proceedings by Takagi et al.

Figure 2 shows the JMA seismic network. A considerable number of stations are also telemetered for quick location mainly for the tsunami warning service. In addition to the stations, many high-gain stations will be deployed on land and ocean bottom in order to improve the lower threshold of detection and location of earth-

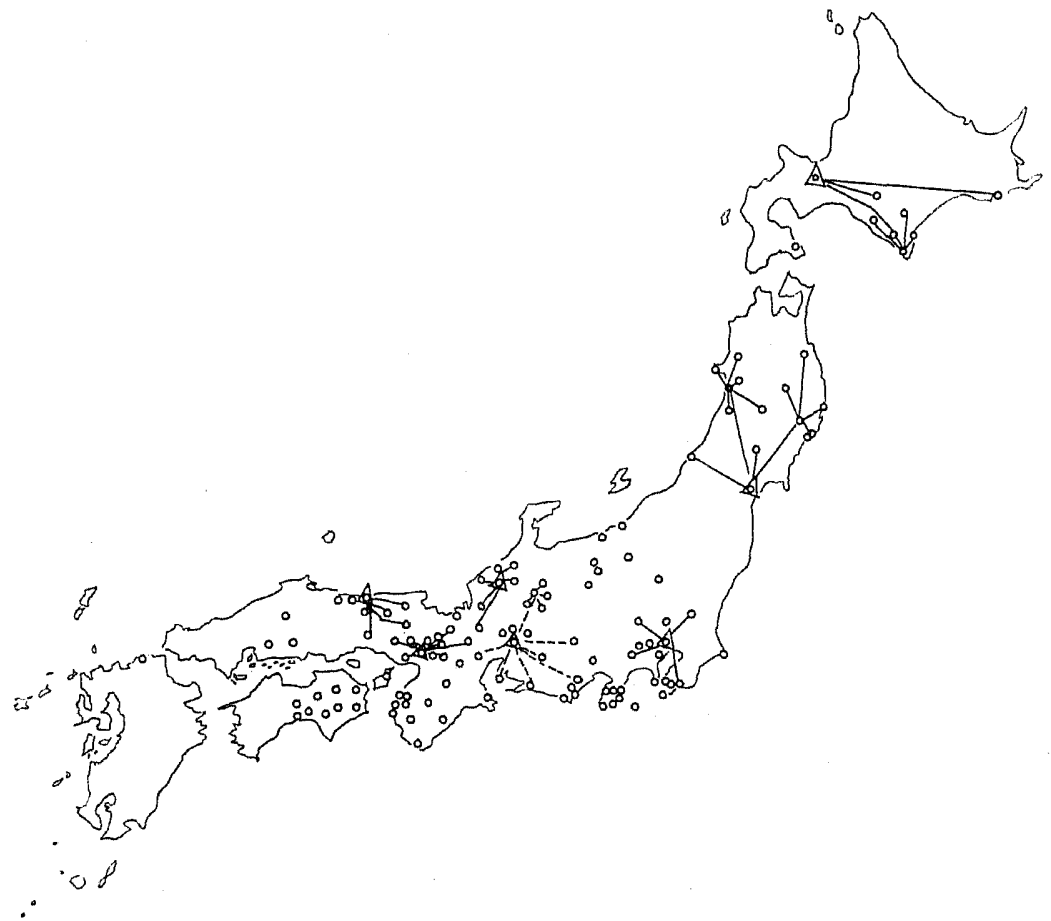

Fig. 1. Distribution of stations for micro-earthquake observation. O, telemetered station; $\triangle$, network center. 


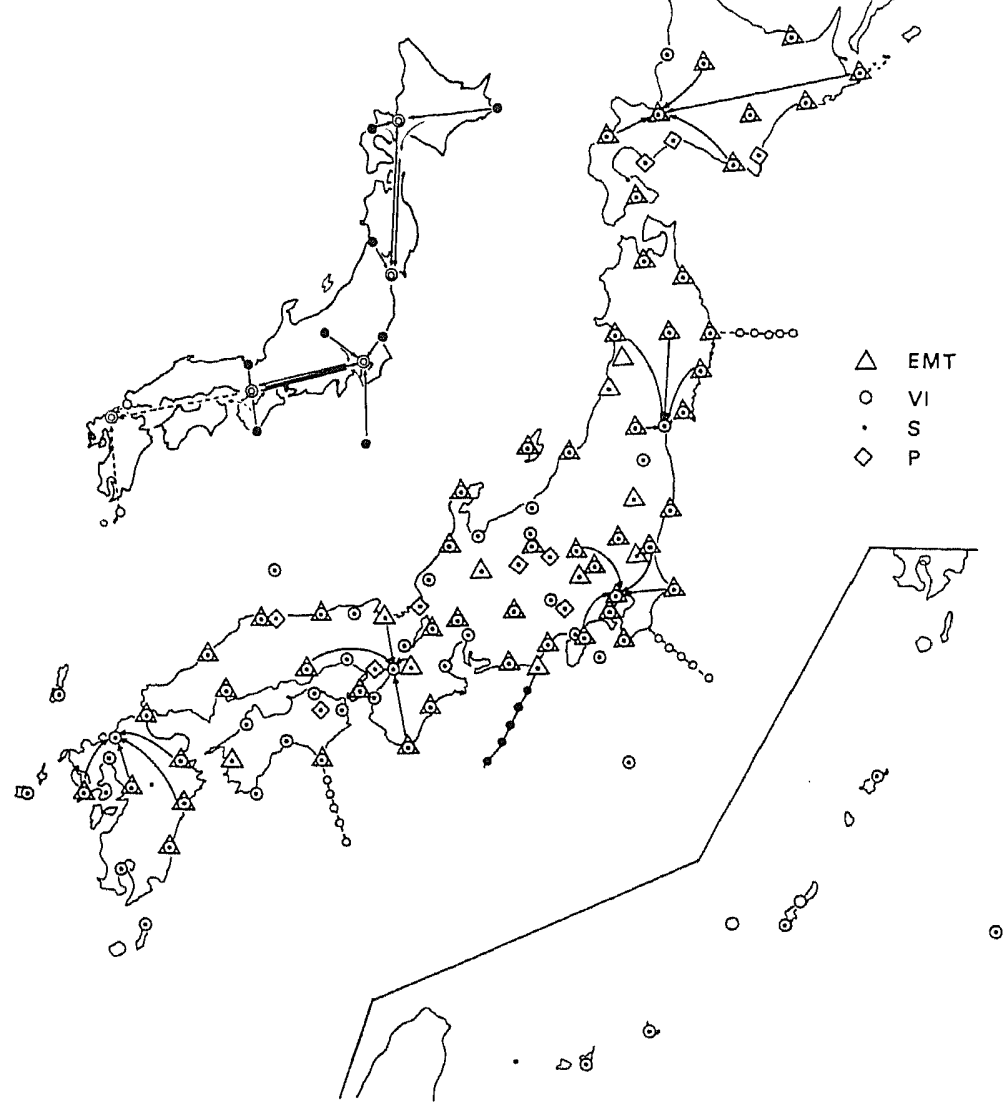

Fig. 2. Distribution of stations equipped with seismographs, JMA (Refer to Seismol. Bull., No. 1, 1976).

quakes in and near Japan from $M 3.5$ to 3.0 in a few years. Seismic records on magnetic tapes are analysed with a higher accuracy and efficiently by an automated processor installed in JMA.

The universities have also "Task Forces" armed with mobile equipment in addition to their fixed stations. They are extremely powerful for observations for aftershocks or swarm-type activities. Figure 3 exhibits a recent results obtained from observations for aftershocks of the Off-Izu Peninsula Earthquake of 1974, conducted by universities' temporary high-gain stations. A close relationship between aftershock activities and active faults is evident from the plots (RESEARCH GROUP FOR Aftershocks, 1975). 


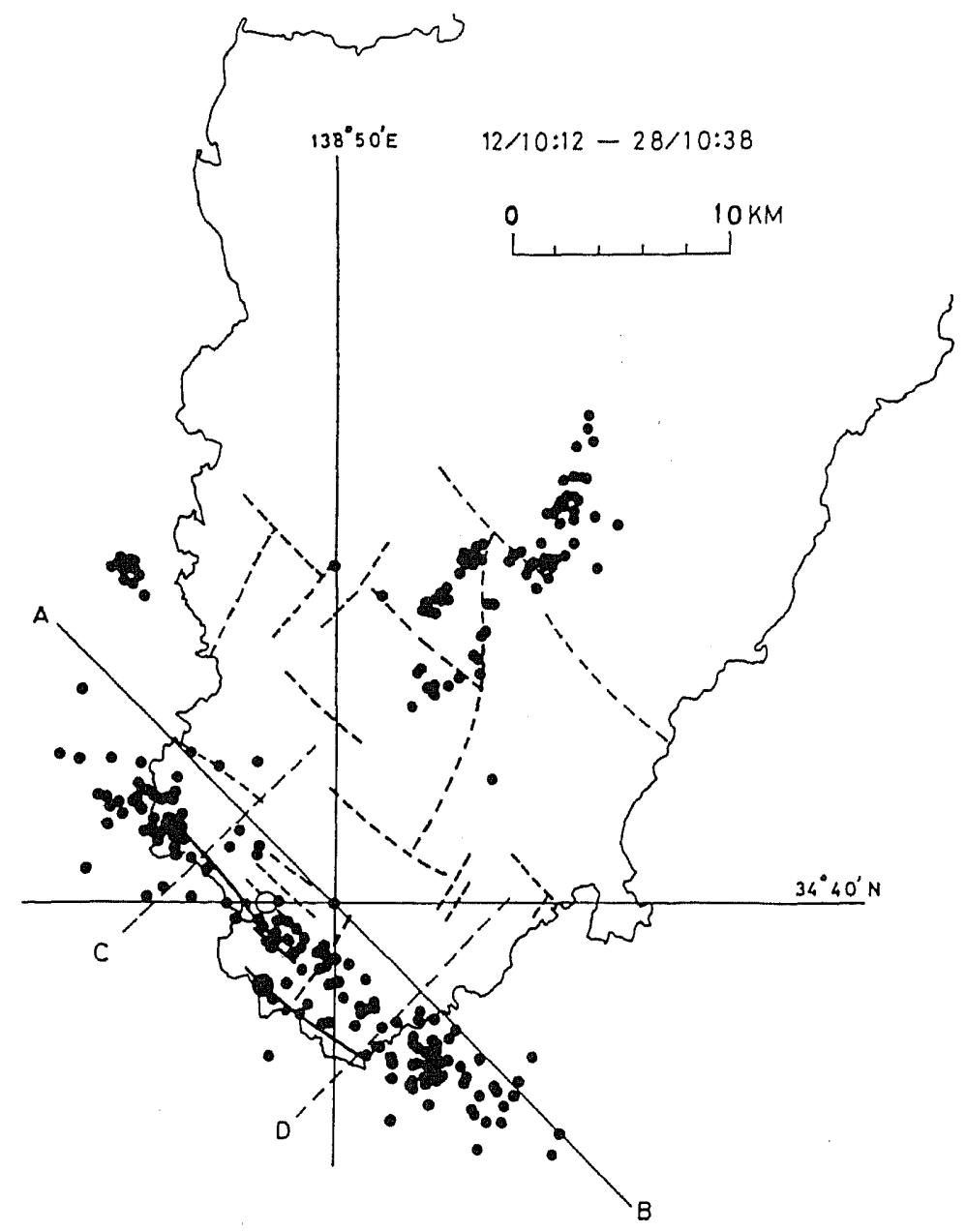

Fig. 3. Distribution of epicenters of main and after-shocks of the Off-Izu Peninsula earthquake of 1974. Large solid circle, main shock; small solid circles, aftershock; thick line, active fault.

\section{Variation in $V_{p}$ or $V_{p} / V_{s}$}

In the last four or five years, under strong influence of the studies made in the Soviet Union and the United States, many past Japanese earthquakes have been studied to see whether or not there had been any change in $V_{p} / V_{s}$ or $V_{p}$ before these events, mainly using JMA data (for example, OHtake, 1973; UTsu, 1973; SekrYA et al., 1974; Terashima, 1974; Ichikawa, 1975; Sexiya et al., 1975; Utsu, 1975; IrzUKA, 1976a, b). It is necessary to mention that similar researches were already conducted in Japan by HAYAKAWA (1950) in early 1950's.

Recent results are shown in Fig. 4. Both positive and negative results were obtained. Some events, however, gave inconsistent results according to different 


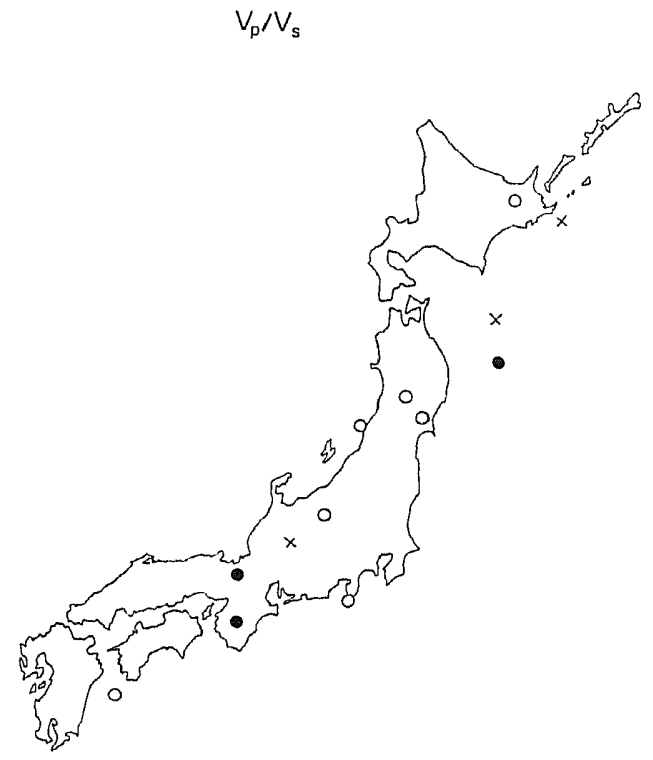

Fig. 4. Distribution of earthquakes used in the studies of temporal variation in seismic velocities. $O$, variation in $V_{p}$ or $V_{p} / V_{s}$; no variation; $\times$, ambiguous.

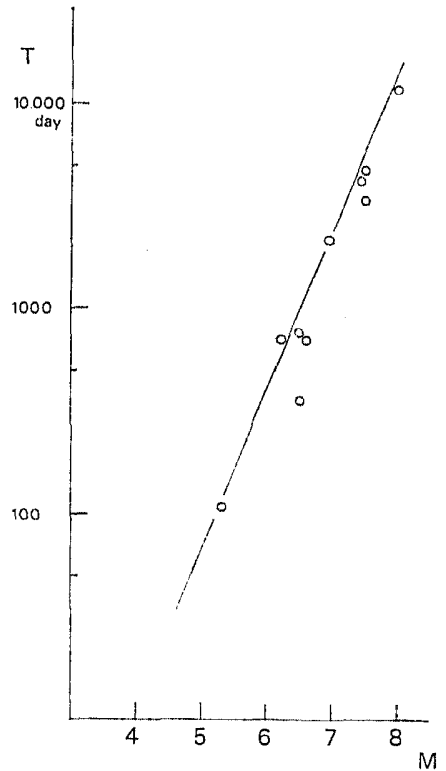

M
Fig. 5. Relationship between precursor time $T$ and earthquake magnitude $M$, for which velocity change was detected. The straight line shows the relationship between $T$ and $M$ proposed by SCHOLz et al. (1973).

methods employed. A very recent study by Ohtake suggests that even positive cases should be rechecked because of the present accuracy of observations.

Figure 5 exhibits a relationship between precursor time $T$ and magnitude $M$ obtained from the earthquakes shown in Fig. 4, in which some change seems to 


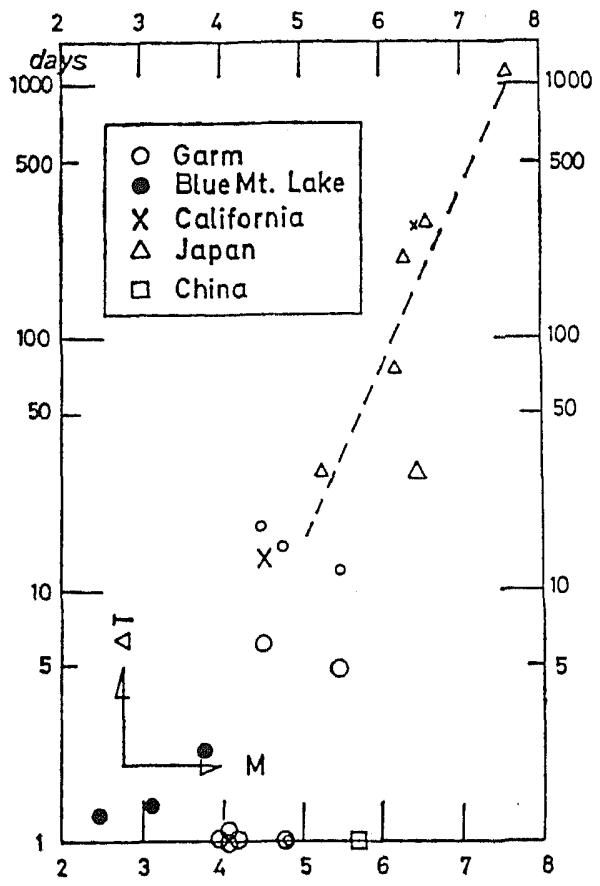

Fig. 6. Relationship between time from the recovery of $P$ wave velocity to the occurrence of main shock $\Delta T$ and earthquake magnitude $M$.

have taken place in $\mathrm{P}$ wave velocity. The relation between $T$ and $M$ appears to be compatible with the one proposed by ScHolz et al. (1973).

Another interesting relationship between the time from the recovery of $P$ velocity change to the occurrence of main shock $\Delta T$ and magnitude $M$ was found by SANTo (1975) (Fig. 6). If the change in $V_{p}$ or $V_{p} / V_{s}$ is routinely monitored in the future, this kind of relation will serve to predict the time of occurrence of expected earthquakes.

\section{Seismicity Gap}

It is evident from many examples that a seismicity gap suggests the area where a great earthquake will occur (INOUYE, 1965; MogI, 1968; UTsU, 1972). Figure 7 is a famous figure presented by UTSU (1972). An earthquake of $M 7.4$ occurred in June 1973 exactly as he had predicted. From the fact that the aftershock region of this event was somewhat smaller than the seismicity gap, which had been pointed out by UTSU (1972), and also the fact that the crustal deformation prior to the earthquake was not fully recovered, it was once suspected that the seismicity gap was not completely taken care of by this event. In other words, even a larger earthquake might occur in the same region in the near future. Later JMA relocated with a higher accuracy events in and near Japan in the period from 1926 to 1960. The distribution 


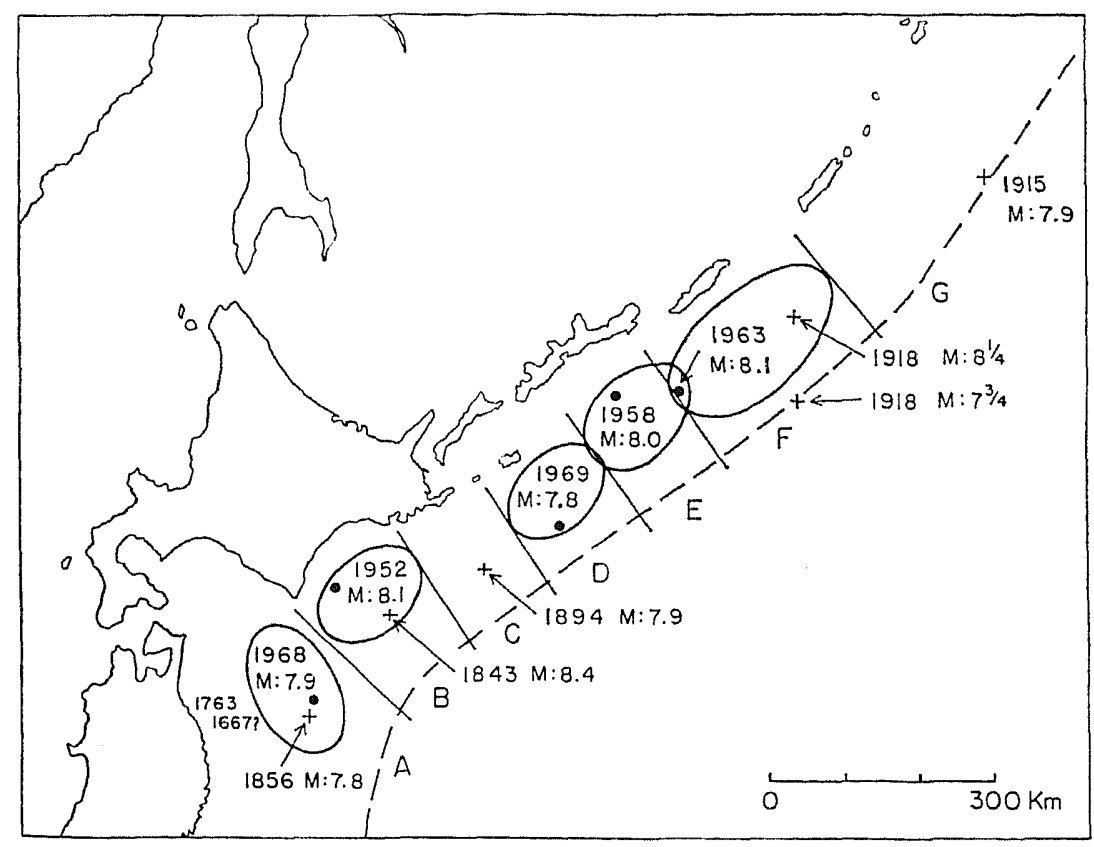

Fig. 7. Seismicity gap off Nemuro Peninsula.

of relocated aftershocks of the Tokachioki Earthquake of $M 8.1$ in 1952 suggests that the aftershock region of this event was larger than the one which had been considered to be at that time, so that the actual seismicity gap was smaller than the gap which Utsu had considered based on the old JMA data (SEkIYA et al., 1974).

Presently, from the view point of seismicity, it appears that this seismicity gap was completely filled by the 1973's earthquake, though some problem still remains in relation to the geodetic observations (refer to Abe's paper in this volume (ABE, 1977)).

According to recent studies, this seismicity gap theory seems to be applied also to comparatively small earthquakes occurring inland OHTAKE (in press).

A map of energy release of earthquakes shallower than $70 \mathrm{~km}$ in the period from 1926 to 1975 , namely fifty years, is shown in Fig. 8. There are two gaps clearly seen along the Pacific coast of Japan: one is off Kanto coast (A) and the other is off Tokai coast (B). In the former gap, 52 years ago the great Kanto earthquake occurred and this gap is probably not matured enough, but the latter one may have been already due, because 123 years have already passed since the last large one (SekiYa et al., 1975). This is one of the reasons why vigorous discussions are now being made as to this region (UTSU, 1977).

Many studies are made on the patterns of earthquake occurrence in space, time and magnitude, based on the routine observations for a long time. From the study on the earthquakes occurring off the Pacific coast of Japan, UTsU (1974) classified these events into the following three categories: 


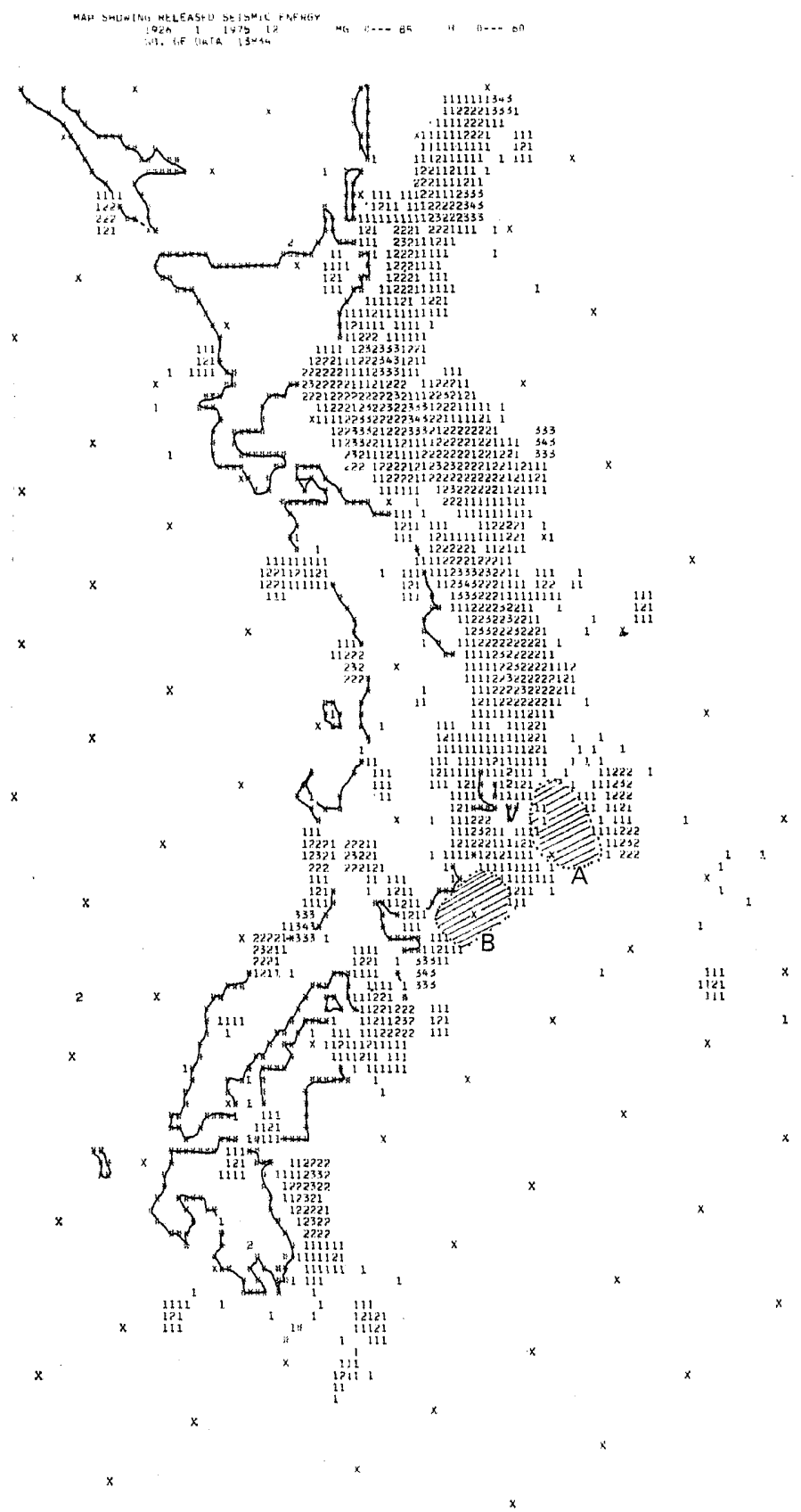

Fig. 8. Map of seismic energy released by shallow earthquakes $(h \leqq 60 \mathrm{~km})$ occurring $1926-$ 1975. Numerals $1,2,3, \ldots$ mean order of $10^{20}, 10^{21}, 10^{22}$ ergs, ..., respectively. -*-*-, coast line; $x$, intersection of meridian and parallel for even degree; 後, seismicity gap (A, off Kanto coast; B, off Tokai coast). 
Type A: Earthquakes of magnitude about 7.5 or more occur at fairly regular intervals. Each earthquake is followed by a standard aftershock activity, but usually preceeded by little foreshock activity. Standard aftershock activity means that the largest aftershock has a magnitude about 1 to 2 unit less than the main shock, and the aftershock frequency decreases regularly with time.

Type B: There is a strong tendency for large earthquakes to occur successively in a limited area, forming a kind of earthquake swarm. Such swarms of large earthquakes recur at relatively short and irregular intervals.

Type AB: Mixed type of A and B. Type A(B) or (A)B means type A or B with slight indication of character of type $B$ or $A$ respectively.

\section{Conclusion}

Needless to say, there have been many other studies based on the continuous seismic observations which are not mentioned in this report because of the space limitation. From these results, it is very clear that the continuous seismic observations are very important from the view point of prediction.

However, mere observation does not mean much. The data must be processed as quickly as possible, if one wants to use the data for prediction. This is very similar to the situation that the accurate weather charts, which tell us what is going on in the atmosphere, are vital for weather forecasting.

In this respect, all the universities' micro-earthquake centers have data processing and location facilities which can operate on real-time or on nearly real-time basis. JMA is also trying to up-grade its data processing capability to the universities' level. And of course our collaboration has been getting closer.

Large earthquakes have been occurring everywhere in the Japanese region. Therefore, the seismic activity in and near Japan must constantly be monitored from large earthquakes down to micro-earthquakes. This goal will be achieved in Japan fairly soon, if we continue our present efforts in developing prediction technique.

\section{REFERENCES}

ABE, K., Some problems in the prediction of the Nemuro-Oki earthquake, J. Phys. Earth, 25, Suppl., S 261-S 271, 1977.

Hayakawa, M., The variation of the seismic wave velocity (Preliminary report), Rep. Geol. Surv. Japan, Special No., 7-24, 1950.

ICHIKAWA, M., Simulation on detection of P wave velocity anomaly by JMA seismological observation system and some related problems, Q. J. Seismol., 40, 43-54, 1975 (in Japanese).

IIzUKA, S., Temporary variations in $V_{p} / V_{s}$ and some related phenomena before the 1968 Tokachi-Oki earthquake, off northeast Japan, Zisin, 29, 247-263, 1976a (in Japanese).

IIzUKA, S., Change in $V_{p} / V_{s}$ before the Tokachi-Oki earthquake of May 16, 1968, off NE Japan, $\mathrm{Na-}$ ture, 260, 415-417, 1976b.

INOUYE, W., On the seismicity in the epicentral region and its neighbourhood before the Niigata earthquake, Q. J. Seismol., 29, 139-144, 1965 (in Japanese).

MAtsumurA, K. and K. Oike, The microearthquake seismicities in and around Japan, Disaster Prev. Res. Inst. Ann., No. 16B, 77-87, 1973 (in Japanese). 
Mogr, K., Sequential occurrence of recent great earthquakes, J. Phys. Earth, 16, 30-36, 1968.

OHTAKE, M., Change in the $V_{p} / V_{s}$ ratio related with occurrence of some shallow earthquakes in Japan, J. Phys. Earth, 21, 173-184, 1973.

OHtake, M., Search for precursor of the 1974 Izu-Hanto-Oki earthquake, Japan, Pure Appl. Geophys. (in press).

RESEARCH GROUP FOR AFTERSHOCKS, Observation of the main and aftershocks of the earthquake off the Izu Peninsula, 1974, Rep. Earthq. off Izu Pen., 1974 and Disaster, 11-32, 1975 (in Japanese).

SANTO, T., On the delay of earthquake occurrence after the end of $V_{p} / V_{s}$ anomaly, Zisin, 28, 101-104, 1975 (in Japanese).

Scholz, C. H., L. R. Sykes, and Y. P. AgGarwal, Earthquake prediction: A physical basis, Science, 181, 803-810, 1973.

Sekiya, H. and K. Tokunaga, On the seismicity gap near Enshunada, Q. J. Seismol., 39, 83-88, 1975 (in Japanese).

Sekiya, H., S. Hisamoto, E. Mochizuki, E. Kobayashi, T. Kurihara, K. Tokunaga, and M. Kishro, The off Nemuro Peninsula earthquake of 1973 and earthquakes off southern part of Hokkaido, Q. J. Seismol., 39, 33-39, 1974 (in Japanese).

TAKAGI, A., A. HASEGAWA, and N. UMINO, Seismic activity in the northern Japan island arc, $J$. Phys. Earth, 25, Suppl., S 95-S 104, 1977.

Terashima, T., Change of $V_{p} / V_{s}$ before the large earthquake of April 1, 1968 in Hyuganada, Japan, Bull. Int. Inst. Seismol. Earthq. Eng., 12, 17-29, 1974.

UTsU, T., Large earthquakes near Hokkaido and expectancy of the occurrence of a large earthquake off Nemuro, Rep. Coord. Comm. Earthq. Predict., 7, 7-13, 1972 (in Japanese).

UTsu, T., Temporal variation in travel time residuals of $\mathbf{P}$ waves from Nevada sources, J. Phys. Earth, 21, 475-480, 1973.

UTSU, T., Space-time pattern of large earthquakes occurring off the Pacific coast of Japanese islands, J. Phys. Earth, 22, 325-342, 1974.

UTsU, T., Detection of a domain of decreased $P$-velocity prior to an earthquake, Zisin, 28, 435-448, 1975 (in Japanese).

UTSU, T., Possibility of a great earthquake in Tokai district, central Japan, J. Phys. Earth, 25, Suppl., S 219-S 230, 1977. 